\title{
Electrogeneration of Poly-N-Methylpyrrole Tosylate Doped Films. Electrochemical and Morphological Study
}

\author{
M.J. González-Tejera* and G. Hervás Martín \\ Dpto. Química Física I. Fac. CC. Químicas. Universidad Complutense. 28040-Madrid, Spain
}

Received 27 September 2006; accepted 17 July 2007

\begin{abstract}
In order to investigate the electrochemical behaviour and morphology under different experimental conditions of poly-N-methylpyrrole doped with sodium $p$ toluensulphonate $(\mathrm{NaTsO})$ in aqueous medium, the doped polymer was potentiostatically synthesized at four potential values: $0.6,0.8,0.9$ and $1.0 \mathrm{~V}$. The morphological study reveals a compact texture in these polymeric films; after being submitted to a positive potential those films were wrinkled. Cyclic voltammetry was used to characterize polymer films ( $\mathrm{pNMPy} / \mathrm{TsO}$ ). The corresponding voltammograms revealed a reversible doping/de-doping process in those films obtained at $\eta_{\mathrm{p}}=0.8 \mathrm{~V}$. Different parameters such as: negative potential limit $\left(E_{i}\right)$, positive potential limit $\left(E_{f}\right)$, sweep rate (v) and continuous cycling were varied.
\end{abstract}

Keywords: conducting polymers, poly-N-methylpyrrole, tosylate anion.

\section{Introduction}

pNMPy is one of the conducting polymer that has attracted a great deal of attention in the last decades since the publication of Kanazawa et al. [1]. In that work they prepared copolymers by electrolysis of mixtures of pyrrole (Py) and N-methylpyrrole (NMPy). They were able to vary copolymer conductivity from insulating to metallic values by five orders of magnitude by selecting the copolymer composition in the films.

With these ideas in mind, many researchers have generated copolymers with pyrrole and N-methylpyrrole [2, 3].

Novák et al. [4] copolymerized Py and NMPy in an attempt to use these films as electrodes in batteries. Copolymers containing different proportions of monomers were prepared electrochemically at various temperatures, demonstrating that the twisting chain conformation for the NMPy units, the structural anisotropy and the

\footnotetext{
* Corresponding author. E-mail address: mjgonte@quim.ucm.es
} 
intermediate values of conductivity were all dependent on the dopant anion [5, 6].

Composite materials are also produced with pNMPy as organic sensors [7-10,11] or for getting blends with good mechanical properties [12]. Biosensors with conducting polymers such as poly-N-methylpyrrole for inmobilizing enzymes have been constracted [13]. Maksymiuk et al. reported conditions for the production of bilayers in which the outer component was pNMPy doped with perchlorate or chloride ions [14-16].

Some authors have verified the influence of the supporting electrolyte $[17,18$, 19] and the polymerization temperature on electrical and mechanical properties of pNMPy and in copolymers with pyrrole in relation to its dielectric properties and charge transport mechanism [20-22].

Mitchell et al. [23] reported that polypyrrole doped with sodium ptoluensulphonate exhibited an anisotropic molecular organization with pyrrole units and toluene sulphonate ions distributed parallel to the electrode surface. This fact probably influences on the polymer texture. As confirmed Zotti et al. [24], the tosylate anion ( $\left.\mathrm{TsO}^{-}\right)$produces an ordered polypyrrole matrix whose electrical conductivity and morphology are affected by the presence of very basic anions such as $\mathrm{OH}^{-}$. In this direction, our group studied the influence of $\mathrm{pH}$ on pNMPy electrochemically synthesized in aqueous solution by FTIR spectroscopy [25].

According to the $\mathrm{pH}$-potential diagram [26], the structure of pNMPy contains two protonation sites with different $\mathrm{pK}_{\mathrm{a}}$ values. The more basic site is related to the nitrogen in the $\mathrm{N}$-methyl group and the other site is the $-\mathrm{N}-\mathrm{CH}_{2}-$ group, in which the methylene is bonded on a pyrrole ring. The existence of two kinds of nitrogen with different basicity suggests that the polymer has two different structures. At least six intermediate forms have been reported during the electron transfer mechanism, depending on the $\mathrm{pH}$, the synthesis technique and the medium.

The aim of this work was to study the electrochemical behaviour of $\mathrm{pNMPy} / \mathrm{TsO}$, analysing its electroactivity by cyclic voltammetry, as a function of different parameters such as potential sweep rate (v), different positive and negative potential limits ( $E_{f}$ and $E_{i}$, respectively), and cycling and its morphology under different synthesis conditions.

\section{Experimental}

$\mathrm{N}$-methylpyrrole (99\% purity) and sodium p-toluensulphonate (95\% purity) were Aldrich products. The monomer was distilled under vacuum and stored in the dark at low temperature without air. The aqueous electropolymerization solution concentrations were $0.1 \mathrm{M} \mathrm{NMPy}+0.1 \mathrm{M} \mathrm{NaTsO}$ in ultra pure water (system Milli-Q from Millipore), $\mathrm{pH}=4.6$ in all the synthesis solutions. $\mathrm{pNMPy} / \mathrm{TsO}$ films were synthesized potentiostatically at four different potentials: $\eta_{p}=0.6,0.8,0.9$ and $1.0 \mathrm{~V}$. The electropolymerization time was generally $t_{p}=20 \mathrm{~s}$. The experiments were run at room temperature in a nitrogen atmosphere. Electrodeposition and cyclic voltammetry measurements were performed with a 
EG\&PAR model 273A potentiostat/galvanostat controlled by PAR Model 270/250 Research Electrochemistry Software 4.00. $\mathrm{pH}$ values were measured with an Orion $710 \mathrm{~A} \mathrm{pH}$-meter. The anodic deposition and the electrochemical characterization of $\mathrm{pNMPy} / \mathrm{TsO}$ films were carried out in two different cells, each having a compartment and three electrodes. A saturated calomel electrode (SCE) was used as reference electrode. Electrical contact between working and reference electrode was achieved through a Luggin capillary. Platinum sheets were used as counter and working electrodes; these were 7.5 and $2.4 \mathrm{~cm}^{2}$, respectively, and were $1.5 \mathrm{~cm}$ apart. Working electrodes were polished with alumina $(0.3 \mu \mathrm{m}$ diameter. Buehler Micropolish) and diamond paste (1 $\mu \mathrm{m}$ diameter, Buehler Metadi); they were then cleaned in acetone in an ultrasonic bath and washed with water and hot concentrated sulphuric acid before final rinsing with Milli-Q water and drying.

Polymer morphology was examined on both faces and on cross sections by scanning electron microscopy in a JEOL model JSM640 microscope at $20 \mathrm{KV}$ with varying magnification. Polymer films were glued with graphite paste to a copper holder and then sputter-coated with a thin gold film to prevent charge buildups due to their low conductivity. Metallizing produced no observable effects on the morphology of deposits.

Infrared spectra were recorded at room temperature directly from the film deposited on Pt electrodes in a FTIR spectrometer Nicolet-Magna 750, using a Spectratech IR-Plan Advantage Microscope.

Conductivity values were measured with a Keithley model 2000 multimeter.

\section{Results and discussion}

\section{Electropolymerization of $p N M P y / T s O$ films}

In electrodic processes the applied potential is directly related to the structure, morphology and electrochromism of the new polymeric phase. Therefore, in this work four electropolymerization potentials have been applied. Fig. 1 shows the synthesis chronoamperograms of $\mathrm{pNMPy} / \mathrm{TsO}$ films at $0.6,0.8,0.9$ and $1.0 \mathrm{~V}$. At 0.6 and $0.8 \mathrm{~V}$ curves described the characteristic steps of double layer charge (I) and monomer diffusion, followed by nucleation (II) and growth (III) of the polymer films. At higher potential values, only steps II and III were registered. In order to examine the polymer generation rate, the experimental polymerisation charge densities $\left(Q_{p}\right)$ measured from these figures by integration were plotted against $\eta_{p}$ at three different $t_{p}$ values (Fig. 2).

Three linear relationships were obtained with slopes: $0.021 \pm 4 \times 10^{-3}$ at $\mathrm{t}_{\mathrm{p}}=5 \mathrm{~s}$; $0.01 \pm 2 \times 10^{-3}$ at $t_{p}=10 \mathrm{~s}$ and $0.005 \pm 8.4 \times 10^{-4}$ at $t_{p}=20 \mathrm{~s}$. This indicates that the polymer generation is delayed at short times. As Fig. 2 shows, there was no polymer generation below $0.6 \mathrm{~V}$. As it is published with other monomers NMethylpyrrole discharge occurred more readily on polymer layers than on the bare $P t$ surface [27]. A linear fit between $Q_{p}$ and $t_{p}$ was obtained for each potentiostatic experiment. The rates of charge consumption $\left(\Delta \mathrm{Q}_{\mathrm{p}} / \Delta \mathrm{t}_{\mathrm{p}}\right)$ were 0.16 $\pm 0.004\left(\eta_{\mathrm{p}}=0.6 \mathrm{~V}\right) ; 1.32 \pm 0.003\left(\eta_{\mathrm{p}}=0.8 \mathrm{~V}\right) ; 3.08 \pm 0.005\left(\eta_{\mathrm{p}}=0.9 \mathrm{~V}\right)$ and $3.72 \pm 0.014\left(\eta_{p}=1.0 \mathrm{~V}\right)$. The influence of the highest potential was evident in 
all cases. These values remained constant over $20 \mathrm{~s}$, clearly indicating that there was no change in the nucleation mechanism during this time. These slopes are one order of magnitude smaller than those obtained with other conducting polymers $[28,29]$.

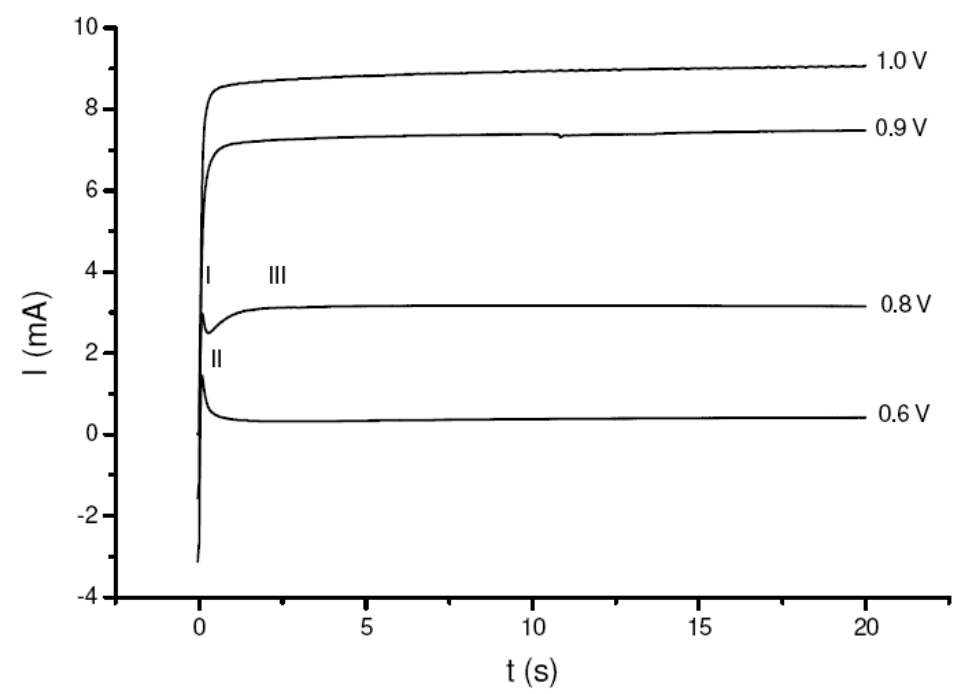

Figure 1. Chronoamperograms of pNMPy/TsO obtained at different electropolymerization potentials. $t_{p}=20 \mathrm{~s} .[\mathrm{NMPy}]=[\mathrm{NaTsO}]=0.1 \mathrm{M}$.

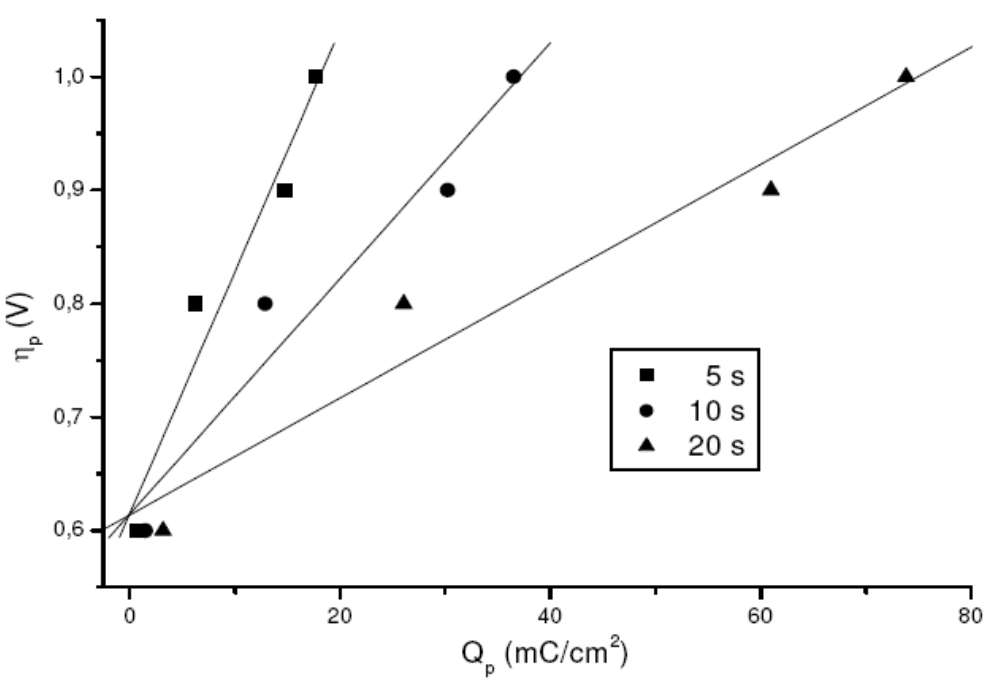

Figure 2. Evolution of polymerisation charge density with polymerisation potential and time.

Both parameters, $\eta_{p}$ and $t_{p}$, have a considerable influence on the quality of the polymer and on the kinetics of nucleation and growth of the new polymeric phase.

Scanning electron microscopy (SEM) was used to examine the texture of the $\mathrm{pMPy} / \mathrm{TsO}$ films as a function of these two parameters. Some films were grown for a long time (20 and 45 minutes) in order to have thick films with the same electrolytic conditions. Fig. 3 shows the morphology of the side in contact with 
the electrolytic solution faced to the counter electrode at $\eta_{p}=0.8 \mathrm{~V}$. This figure depictes the typical cauliflower texture that became smooth with more growth centres when the higher potential was applied. The same effect was observed when $t_{p}=45$ min. Cross-sections of the two films confirmed that the internal structure of $\mathrm{pNMPy} / \mathrm{TsO}$ was more compact than other conducting polymers such as pPy doped with the same counter anion [30] or polyfuran doped with a smaller counter anion [31]: see Fig. 4.

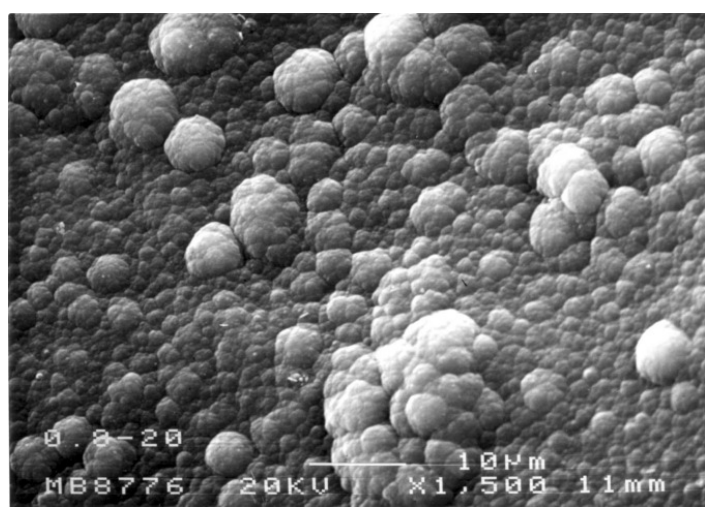

Figure 3. Scanning electron micrograph of pNMPy/TsO films. $t_{p}=20$ min. $\eta_{p}=0.8 \mathrm{~V}$. Side faced to the counter electrode.

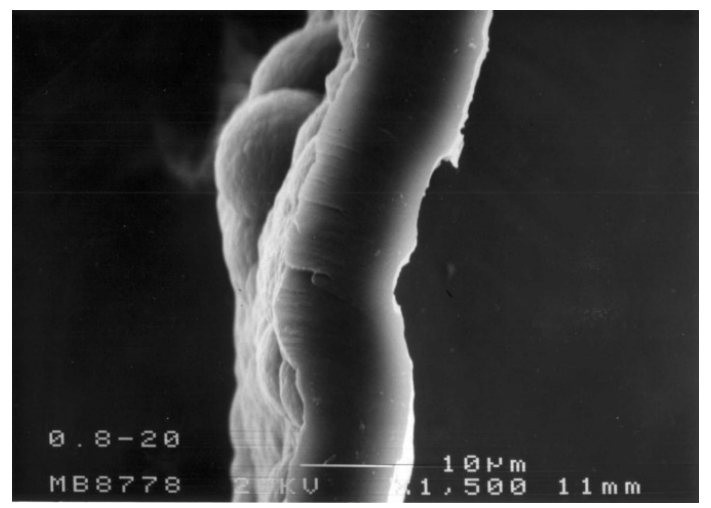

Figure 4. Scanning electron micrograph of the cross-section of $\mathrm{pNMPy} / \mathrm{TsO}$ films. $\eta_{\mathrm{p}}=$ 0.8 V. Same film of Fig. 3.

Films obtained at $0.8 \mathrm{~V}$ with $\mathrm{t}_{\mathrm{p}}=45 \mathrm{~min}$ exhibited electrochemomechanical properties. When these films were taken off the electrode their planar aspect immediately changed to that depicted in Fig. 5. This change was not produced by any applied potential. The film was in a doped oxidation state, $\eta_{p}=0.8 \mathrm{~V}$, therefore according to reference 29 in this state the polymeric chain would tend to expand continuously due to different facts: repulsions between the positive charges stored along the chain or rearrangements of the double bonds or strong coulombic polymer-counter ion interactions, etc. The result is an spectacular contraction of the geometry of the material when the potential effect ended. This electromechanical property has been extensively studied in polypyrrole, polythiophene, polyaniline and its derivatives [32-34]. 
It has been reported that pNMPy is a promising material in electrochromic displays [35]. We observed that films obtained at $0.6 \mathrm{~V}$ were a pale matte yellow on both electrode faces, the colour being always more intense on the face opposite the counter electrode. At $\eta_{\mathrm{p}}=0.8 \mathrm{~V}$ and $0.9 \mathrm{~V}$, however, films presented a sequence of bright colours - yellow, blue, greenish and violet - from the edge of the Pt sheet inwards. At $\eta_{\mathrm{p}}=1.0 \mathrm{~V}$ the colour sequence was similar but more intense. These different tonalities were dependent on film growth [36].

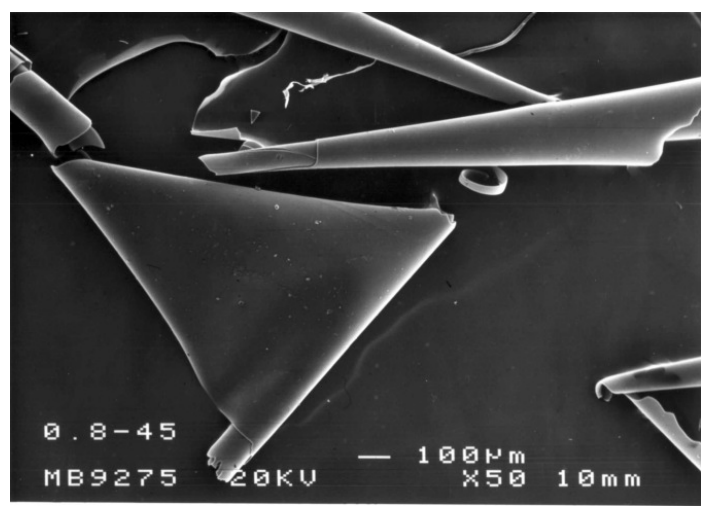

Figure 5. Scanning electron micrograph of $\mathrm{pNMPy} / \mathrm{TsO}$ films obtained at $\mathrm{t}_{\mathrm{p}}=45 \mathrm{~min}$, $\eta_{\mathrm{p}}=0.8 \mathrm{~V}$. Some minutes after to be synthesized and taken off the electrode surface.

Electrochemical characterization of $P N M P y / T s O$

Characterization cycles were carried out in a different cell with the electrolytic medium without monomer, at a potential scan rate of $50 \mathrm{mVs}^{-1}$, from the polymer insulating state $(-0.8 \mathrm{~V})$ to the conducting one $(0.6 \mathrm{~V})$. It is known that some relaxation effect is produced on the conducting polymer structure during the first potential cycles [37], therefore we considered second cycles more representative of the polymer behaviour except when continuous cycling was studied.

Fig. 6 shows the characteristic cyclic voltammograms (CVs) of a bare $\mathrm{Pt}$ electrode and $\mathrm{pNMPy} / \mathrm{TsO}$ films recorded immediately after polymerisation at three different potentials: $0.6 \mathrm{~V}, 0.8 \mathrm{~V}$ and $1.0 \mathrm{~V}$. Pt and polymeric films obtained at $0.6 \mathrm{~V}$ had the smaller electroactivity. Films generated at the higher potentials have two anodic peaks, $\mathbf{a}$ and $\mathbf{b}$, corresponding to different stages of polymeric matrix oxidation related to dopant anion insertion in the polymeric chain, and the corresponding two reduction peaks, a'and $\mathbf{b}^{\prime}$, related to the deinsertion of the dopant anion. On Table 1 are collected the electrochemical parameters deduced from Fig. 6.

Peak a potential had a negative value and low current density (Table 1). These values indicate that radical-cation polaron-type oxidative states were generated at such low potentials. These states were able to incorporate small amounts of counter anions, while at peak $\mathbf{b}$ potential the polymer oxidation state was higher, particularly in films obtained at $1.0 \mathrm{~V}$ with a higher current density. This suggests that a large number of counterions entered the polymer matrix and were more strongly bonded due to the higher oxidation charge density ( $\left.Q_{o x}\right)$. 
Bipolaron-type oxidation states could probably be generated at these high potentials. Film thicknesses were calculated from reference data [36].

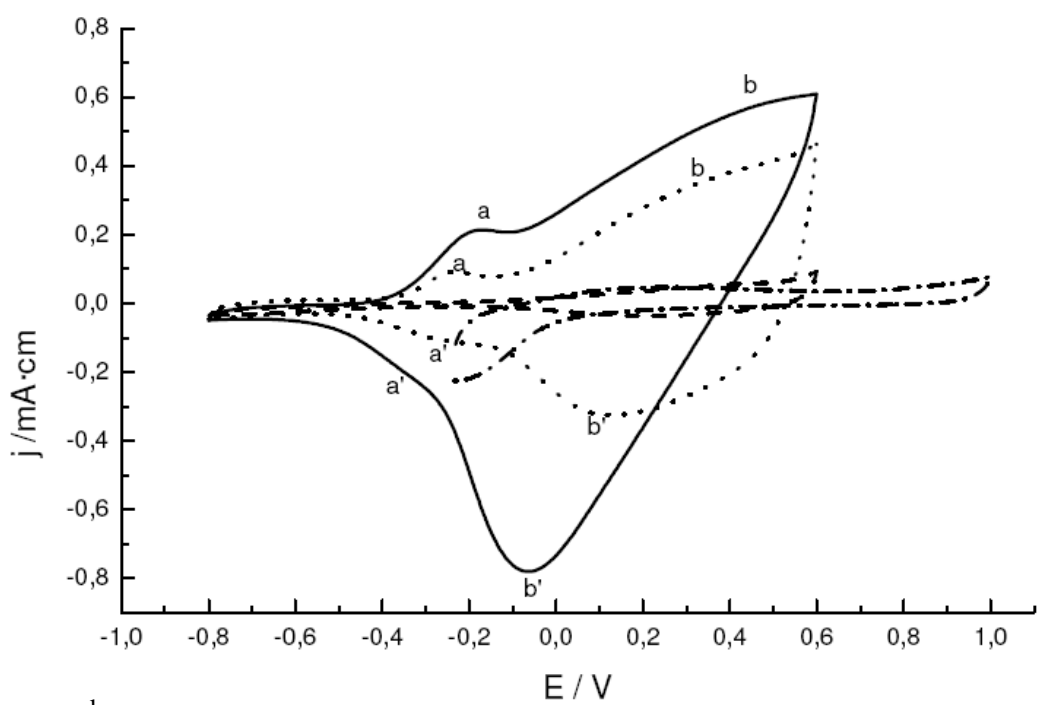

Figure 6. CVs $\left(2^{\text {nd }}\right.$ cycle $)$ of $\mathrm{pNMPy} / \mathrm{TsO}$ films electrodeposited at $\eta_{\mathrm{p}}=0.6 \mathrm{~V}(---), 0.8$ $\mathrm{V}(\cdots)$ and $1.0 \mathrm{~V}(-)$. CV of Pt electrode in the same electrolytic medium (----). $[\mathrm{NaTsO}]=0.1 \mathrm{M} . \mathrm{v}=50 \mathrm{mV} \cdot \mathrm{s}^{-1}$.

As Fig. 6 shows an intermediate state of oxidation in these films was observed when $\eta_{p}=0.8 \mathrm{~V}$. The values of $\mathrm{j}_{\mathrm{p}}{ }^{\mathrm{a}} / \mathrm{j}_{\mathrm{p}}{ }^{{ }^{\prime}}$ and $\mathrm{j}_{\mathrm{p}}{ }^{\mathrm{b}} / \mathrm{j}_{\mathrm{p}}{ }^{\mathrm{b}^{\prime}}$ ratios were very close to unity as deduced from Table 1, indicating that both oxidation and reduction processes were highly reversible [37]. It was not the same for films obtained at $1.0 \mathrm{~V}$.

In the three deposits represented in Table 1, the total oxidation and reduction charge densities ratio were greater than one and so $\mathrm{Q}^{\mathrm{T}}$ ox $>\mathrm{Q}^{\mathrm{T}}$ red. This indicates that $\mathrm{pNMPy} / \mathrm{TsO}$ facilitated the insertion of the tosylate anion remaining in the chain, as it is verified by FTIR.

Fig. 7 shows cyclic voltammograms recorded from variable negative potentials, $\mathrm{E}_{\mathrm{i}}$, to a constant positive value $\mathrm{E}_{\mathrm{f}}=0.6 \mathrm{~V}$ for $\mathrm{pNMPy} / \mathrm{TsO}$ films obtained at 0.8 V. The purpose of these experiments was to neutralise the positive charges (polaron and bipolaron-type) generated in the polymer in the previous cycle. That is, to have the polymer matrix in a reduced state. The insulating state tended to increase as $\mathrm{E}_{\mathrm{i}}$ diminished and when the $\mathrm{Q}^{\mathrm{T}}{ }_{\text {red }} / \mathrm{Q}^{\mathrm{T}}$ ox ratio reached the unity at a specific $E_{i}$ value. $Q^{T}$ red $/ Q^{T}$ ox was 1.04 when $E_{i}=-0.3 \mathrm{~V}, 0.95$ when $E_{i}=-0.7 \mathrm{~V}$ and 1.04 when $E_{i}=-0.8 \mathrm{~V}$ for films obtained at $0.8 \mathrm{~V}$. Similar values of $\mathrm{Q}^{\mathrm{T}}$ red $/$ $\mathrm{Q}^{\mathrm{T}}$ ox ratio were obtained when $\eta_{\mathrm{p}}=0.6$ and $1.0 \mathrm{~V}$. As the polymer was in a higher oxidation state, a more negative potential to reduce him was required. The potential of the dopant insertion and de-insertion processes described by peaks $\mathbf{a}$, $\mathbf{b}$ and $\mathbf{a}^{\prime}, \mathbf{b}^{\prime}$ were almost constant, and there was a slight increase in their current densities (Fig. 7). That could mean that in these films the permeability of dopant anions in successive charge-discharge cycles was reversible.

As noted in the Introduction, we are interested in the behaviour of the polymer when submitted to increasing oxidation states that produce hole injections in the valence band of the $\mathrm{pNMPy} / \mathrm{TsO}$ structure. Therefore CVs were run from a 
constant negative potential, $\mathrm{E}_{\mathrm{i}}=-0.8 \mathrm{~V}$, to increasing $\mathrm{E}_{\mathrm{f}}$ values from 0.0 to $0.8 \mathrm{~V}$ in steps of $0.1 \mathrm{~V}$.

Table 1. Characterization parameters. $\eta_{\mathrm{p}}$ : electropolymerization potential; $\mathrm{j}_{\mathrm{p}}$ : peak current density; $\mathrm{E}_{\mathrm{p}}$ : peak potential; $\mathrm{Q}^{\mathrm{T}}{ }_{\text {ox }}$ : total oxidation charge density; $\mathrm{Q}^{\mathrm{T}}{ }_{\text {red }}$ : total reduction charge density; $\delta$ : film thickness deduced from polymerisation charge density, reference [36].

\begin{tabular}{|c|c|c|c|}
\hline$\eta_{\mathrm{p}} / \mathrm{V}$ & 0.6 & 0.8 & 1.0 \\
\hline $\mathrm{j}_{\mathrm{p}}^{\mathrm{a}} / \mathrm{mA} \mathrm{cm}{ }^{-2}$ & --- & 0.092 & 0.214 \\
\hline$-E_{p}^{a} / V$ & --- & 0.24 & 0.174 \\
\hline $\mathrm{j}_{\mathrm{p}}^{\mathrm{b}} / \mathrm{mA} \mathrm{cm}^{-2}$ & 0.038 & 0.29 & 0.446 \\
\hline $\mathrm{E}_{\mathrm{p}}^{\mathrm{b}} / \mathrm{V}$ & 0.226 & 0.226 & 0.236 \\
\hline $\mathrm{Q}_{\mathrm{ox}}^{\mathrm{T}} / \mathrm{mC} \mathrm{cm}^{-2}$ & 1.01 & 4.7 & 8.03 \\
\hline$-\mathrm{j}_{\mathrm{p}}{ }^{\mathrm{a}} / \mathrm{mA} \mathrm{cm}$ & --- & 0.105 & 0.172 \\
\hline$-E_{p}^{a^{\prime}} / V$ & --- & 0.27 & 0.38 \\
\hline$-\mathrm{j}_{\mathrm{p}} \mathrm{b}^{\prime} / \mathrm{mA} \mathrm{cm}{ }^{-2}$ & 0.036 & 0.324 & 0.78 \\
\hline $\mathrm{E}_{\mathrm{p}}^{\mathrm{b}^{\prime}} / \mathrm{V}$ & 0.222 & 0.138 & 0.06 \\
\hline $\mathrm{Q}_{\mathrm{red}}^{\mathrm{T}} / \mathrm{mC} \mathrm{cm}^{-2}$ & 0.835 & 4.02 & 7.4 \\
\hline $\mathrm{Q}_{\mathrm{ox}}^{\mathrm{T}} / \mathrm{Q}_{\mathrm{red}}^{\mathrm{T}}$ & 1.2 & 1.16 & 1.08 \\
\hline $\begin{array}{l}\boldsymbol{\delta} / \AA \\
(5 \mathrm{~s})\end{array}$ & ---- & 15.9 & 237.9 \\
\hline$(10 s)$ & ---- & 138 & 558 \\
\hline$(20 s)$ & $\begin{array}{l}--- \\
--\end{array}$ & 349.7 & 1249.8 \\
\hline
\end{tabular}

Figs. $8(\mathrm{a}, \mathrm{b}$ and $\mathrm{c})$ depict the total oxidation and reduction charge densities versus $E_{f}$ for the three films. For films obtained at $0.6 \mathrm{~V}$ (case a), $\mathrm{Q}^{\mathrm{T}}$ red $>\mathrm{Q}^{\mathrm{T}}$ ox except when $E_{f}=0.8 \mathrm{~V}$. Up to this $E_{f}$ value, the dopant anions inserted in the polymer backbone in the oxidation cycle and during the generation process were easily expelled from the polymer. From $\mathrm{E}_{\mathrm{f}}=0.5 \mathrm{~V}$ upwards, there was a change in the mechanism of tosylate anion insertion, and more oxidation states in the polymer matrix were probably generated, strongly attaching the dopant anions to each $\mathrm{E}_{\mathrm{f}}$ value, so that at $\mathrm{E}_{\mathrm{f}}=0.8 \mathrm{~V}, \mathrm{Q}^{\mathrm{T}}{ }_{\mathrm{ox}}>\mathrm{Q}^{\mathrm{T}}$ red. However, when $\mathrm{E}_{\mathrm{f}}=0.7 \mathrm{~V}, \mathrm{Q}^{\mathrm{T}}$ ox $\cong \mathrm{Q}_{\text {red. }}^{\mathrm{T}}$

In case $\mathrm{b}\left(\eta_{\mathrm{p}}=0.8 \mathrm{~V}\right), \mathrm{Q}^{\mathrm{T}}{ }_{\text {ox }}>\mathrm{Q}^{\mathrm{T}}$ red in all cases. These films were more electroactive and the insertion and de-insertion processes were more reversible because both total charge densities were very similar up to $\mathrm{E}_{\mathrm{f}}=0.5 \mathrm{~V}$. From this potential upwards, bipolaron states were probably generated and dopant insertion was higher.

In the third case $\left(\eta_{p}=1.0 \mathrm{~V}\right)$, the oxidation state of these films was deeper as it is evidenced by comparison of $\mathrm{Q}^{\mathrm{T}}$ values in the three figures. Hence, $\mathrm{Q}^{\mathrm{T}}$ ox $\cong \mathrm{Q}^{\mathrm{T}}$ red for $\mathrm{E}_{\mathrm{f}}<0.4 \mathrm{~V}$; however, when $\mathrm{E}_{\mathrm{f}}=0.4 \mathrm{~V}$ and $0.5 \mathrm{~V}, \mathrm{Q}^{\mathrm{T}}{ }_{\text {ox }}=\mathrm{Q}^{\mathrm{T}}$ red; and finally, for values of $\mathrm{E}_{\mathrm{f}}>0.5 \mathrm{~V}, \mathrm{Q}^{\mathrm{T}}$ ox $>\mathrm{Q}^{\mathrm{T}}$ red, leading to the same conclusions as before.

The influence of the potential scan rate, $\mathrm{v}$, was studied in the range $1-100 \mathrm{mV}$ $\mathrm{s}^{-1}$ with $\mathrm{E}_{\mathrm{i}}=-0.8 \mathrm{~V}$ and $\mathrm{E}_{\mathrm{f}}=0.6 \mathrm{~V}$. This study could provide further insight into 
the mechanism of charge transport in accordance with the theory of triangular potential sweep. The slope of the logarithmic plot of the peak current densities against $\mathrm{v}$ allows us to establish whether the electrodic processes were mass transfer controlled (diffusion mechanism, slope $0.5 \mathrm{~V}$ ) or charge transfer controlled (slope 1.0), and also the degree of mobility of the dopant anions in the polymeric matrix [38].

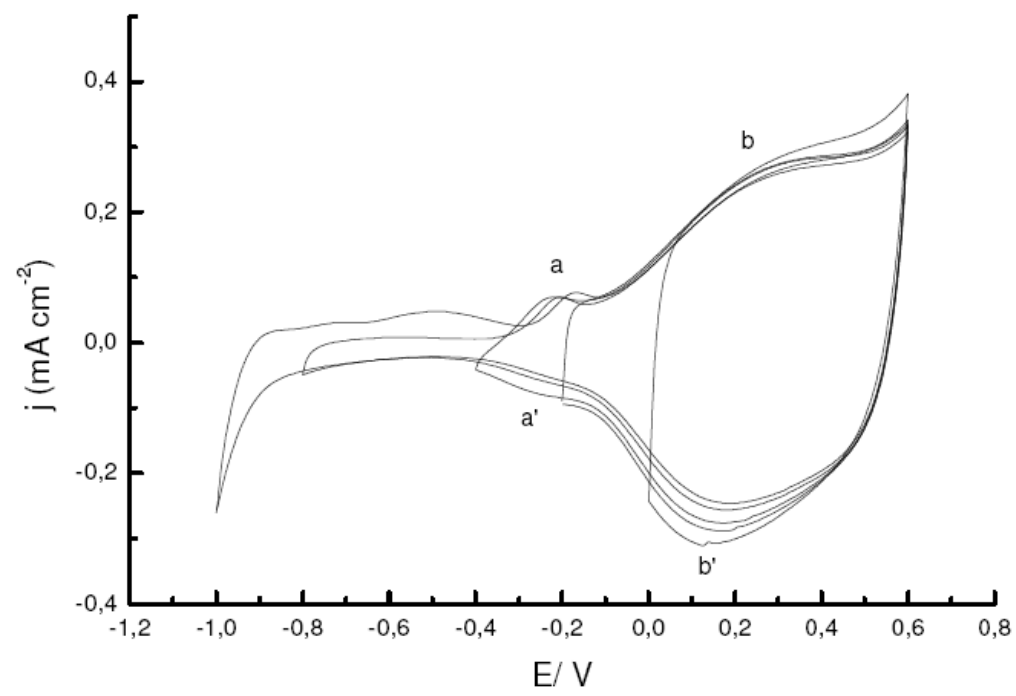

Figure 7. $\mathrm{CVs}\left(2^{\text {nd }}\right.$ cycle $)$ of $\mathrm{pNMPy} / \mathrm{TsO}$ films electrodeposited at $\eta_{\mathrm{p}}=0.8 \mathrm{~V}$ with increasing negative potential limit $\left(\mathrm{E}_{\mathrm{i}}\right)$ in $0.1 \mathrm{M} \mathrm{NaTsO} . \mathrm{v}=50 \mathrm{mV} \cdot \mathrm{s}^{-1}$.

During this study there was major loss of electroactivity in all films. It was difficult to identify the four peaks (a, b and $\left.\mathbf{a}^{\prime}, \mathbf{b}^{\prime}\right)$ in the polymeric deposits obtained at $0.6 \mathrm{~V}$. Current densities of peaks $\mathbf{b}$ and $\mathbf{b}^{\prime}$ were plotted as a function of $\mathrm{v}$ in Fig. 9 ( $\mathrm{a}$ and $\mathrm{b}$ ) for films obtained at 0.8 and $1.0 \mathrm{~V}$, respectively. In Fig. 9a the corresponding slopes were close to unity: $0.98 \pm 0.02$ for the oxidation process (peak b) and $0.92 \pm 0.03$ for the reduction process (peak $\mathbf{b}^{\prime}$ ). In both processes the radical cations were generated by a charge transfer mechanism at all scan rates; this was confirmed by the slopes of the logarithmic plot of $\mathrm{Q}^{\mathrm{T}}$ (oxidation and reduction) against $\mathrm{v}$. The dopant anion exhibited high mobility. However, in the case of Fig. $9 b$ (corresponding to a more oxidised film, $\eta_{p}=1.0$ $\mathrm{V}$ ), the slopes were $0.49 \pm 0.02$ (peak b) and $0.67 \pm 0.02$ (peak b'). A diffusion mechanism of redox processes was prevalent and dopant anion mobility was less. The plot of total oxidation and reduction charge densities as a function of potential sweep rate for $\mathrm{pNMPy} / \mathrm{TsO}$ films obtained at $\eta_{\mathrm{p}}=1.0 \mathrm{~V}$ confirmed that insertion/de-insertion processes were diffusion controlled. Both slopes had the same value, $-0.43 \pm 0.005$. 


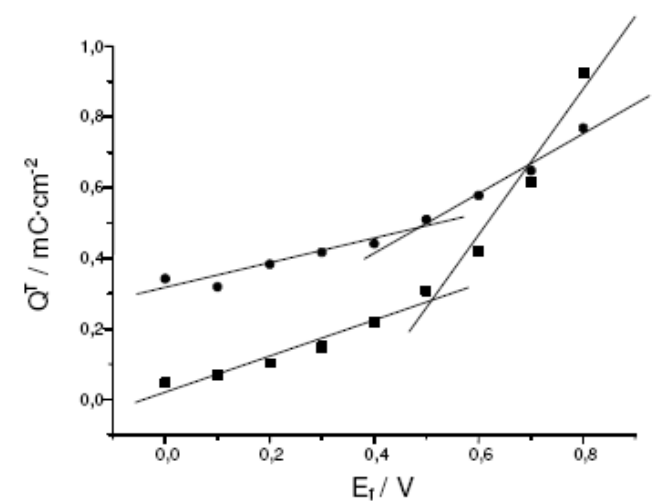

a)

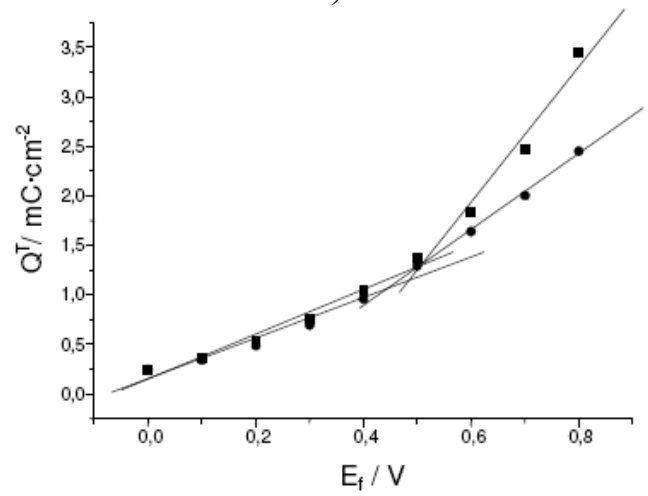

b)

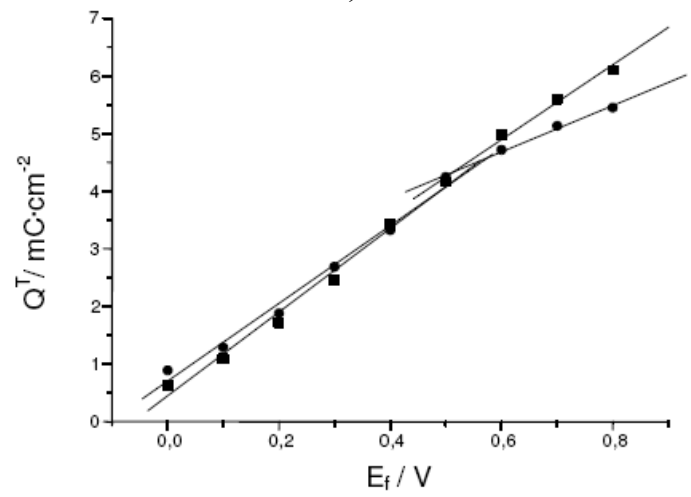

c)

Figure 8. Plot of the total oxidation $(\boldsymbol{\square})$ and reduction $(\bullet)$ charge densities against positive potential limit $\left(\mathrm{E}_{\mathrm{f}}\right)$ for $\mathrm{pNMPy} / \mathrm{TsO}$ films obtained at $\eta_{\mathrm{p}}=0.6 \mathrm{~V}$ (a), $0.8 \mathrm{~V}$ (b) and $1.0 \mathrm{~V}(\mathrm{c})$, respectively.

The infrared spectrum, between 1800 and $500 \mathrm{~cm}^{-1}$, of the oxidized and black $\mathrm{pNMPy} / \mathrm{TsO}$ newly synthesized $\left(\eta_{\mathrm{p}}=0.8 \mathrm{~V}\right)$ is shown in Figure 10 . As described in the literature [25], the band about $1700 \mathrm{~cm}^{-1}, \mathrm{v}(\mathrm{C}=\mathrm{O})$ is attributable to degradation induced by the nucleophilic attack of water. Due to the electropolymerization applied potential, aromatic and quinoid structures must be present in the polymer backbone as is generally accepted [39]. Consequently, the spectrum of the doped polymer exhibits bands at about 1590 and $1552 \mathrm{~cm}^{-1}, \mathrm{v}(\mathrm{C}$ $=\mathrm{C})$ and $\mathrm{v}(\mathrm{C}-\mathrm{C})$ [25] of both structures and those about 1455 and $1433 \mathrm{~cm}^{-1}, \mathrm{v}$ $(\mathrm{C}-\mathrm{N}), \mathrm{v}(\mathrm{C}=\mathrm{C}), \delta(\mathrm{C}=\mathrm{C}-\mathrm{N}), \delta(\mathrm{C}=\mathrm{C}-\mathrm{C})$ in the ring and inter rings. Bands 
observed at about $1197,1015,815$ and $683 \mathrm{~cm}^{-1}$ must be assigned to tosylate, confirming the insertion of the dopant anion in the polymer lattice.

The nature and size of the dopant anions, the nature of the solvent (aqueous or not) and the $\mathrm{pH}$ of the electrolytic solution, all strongly influence the conductivity values. In our experimental conditions, $\eta_{\mathrm{p}}=0.8 \mathrm{~V}$ and $1.0 \mathrm{~V} ; \mathrm{t}_{\mathrm{p}}=20$ min, the mean conductivity value of $\mathrm{pNMPy} / \mathrm{TsO}$ films obtained was $1.10^{-6} \mathrm{~S}$ $\mathrm{cm}^{-1}$.

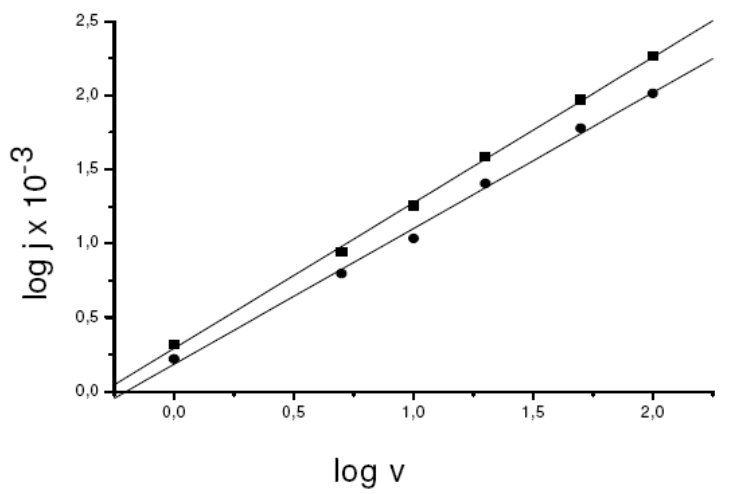

a)

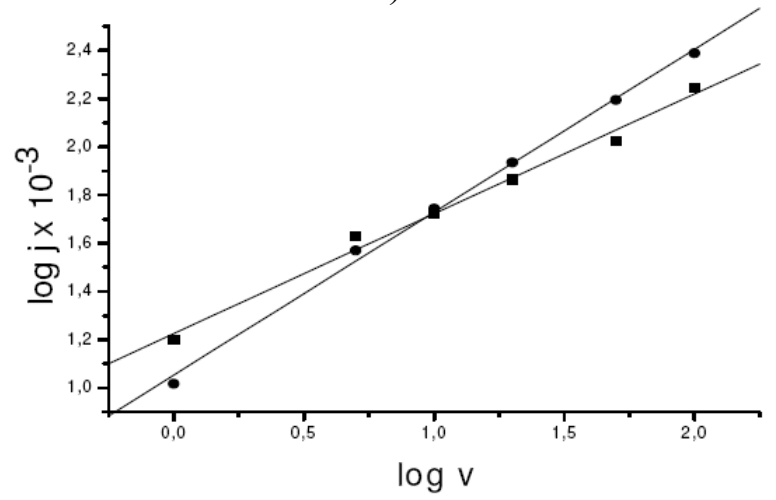

b)

Figure 9. Plot of $\log \mathrm{j}$ against $\log \mathrm{v}$ for peak $\mathrm{b}(\boldsymbol{\bullet})$ and $\mathrm{b}^{\prime}(\bullet)$ for $\mathrm{pNMPy} / \mathrm{TsO}$ films obtained at: a) $\eta_{\mathrm{p}}=0.8 \mathrm{~V}$ and b) $1.0 \mathrm{~V}$.

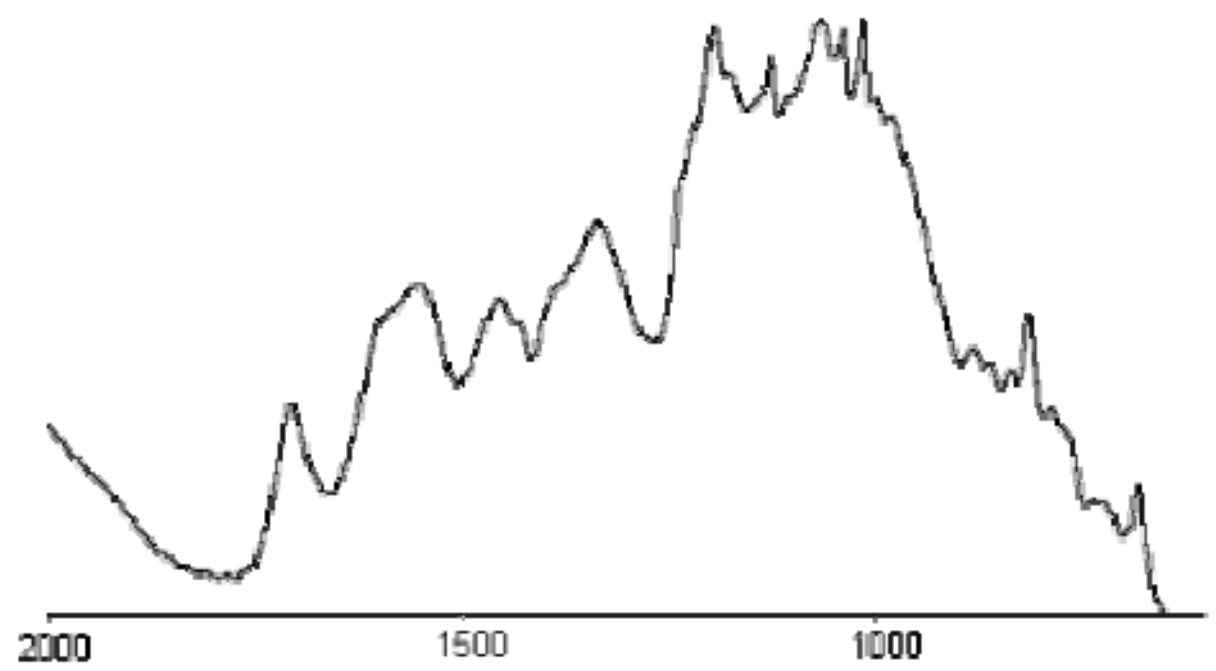

Figure 10. FTIR spectrum of $\mathrm{pNMPy} / \mathrm{TsO}$ obtained at $0.8 \mathrm{~V}$. 
$\mathrm{pNMPy} / \mathrm{TsO}$ films obtained at $0.8 \mathrm{~V}$ were continuously cycled in the potential range -0.8 to $0.6 \mathrm{~V}$ at $\mathrm{v}=50 \mathrm{mV} \mathrm{s}^{-1}$ for $7 \mathrm{~h} 30 \mathrm{~min}, \mathrm{n}=450$ cycles in the background electrolytic solution. Some activation was observed in both insertion/de-insertion processes from $n=1$ to 60 cycles, but there was a deactivation when 450 cycles were recorded.

\section{Conclusions}

This work demonstrates that the electrochemical generation and morphology of pNMPy/TsO films was influenced by synthesis parameters such as potential and time, as in the case of other conducting polymers. The best experimental conditions were $\eta_{p}=0.8 \mathrm{~V}$ and $t_{p}=20 \mathrm{~s}$ but it is interesting to note that polymer generation is delayed at short times. The doping/de-doping processes were reversible and the counter anion mobility was higher. These polymeric films had a compact texture.

From the variation of peak current densities with the scan rate, it was deduced that doping and de-doping processes were produced by a superficial charge transfer mechanism in less oxidised films while a diffusion mechanism was detected when $\eta_{p}$ was higher.

The electrical conductivity value of these films was in the semiconductor range. At higher $t_{p}$ values (20 min and $45 \mathrm{~min}$ ) samples presented a smooth texture rather than the typical cauliflower one. The same effect was observed when the polymerisation potential was changed from $0.8 \mathrm{~V}$ to $1.0 \mathrm{~V}$. That means that $t_{p}$ and $\eta_{p}$ have similar influence on the polymer texture.

Oxidation potentials promote different interactions between positive charges stored along the polymer backbone such as rearrangements of $\pi$-conjugated systems or coulombic polymer-counter anion interactions. The polymer chain consequently contracts when the positive potential is removed, as it is shown in Fig. 5. This could have very useful technological applications.

\section{Acknowledgements}

Authors would like to thank to Spanish DGES, project MAT2002-0095, for financial support.

\section{References}

1. K. Kanazawa, A.F. Díaz, R.H. Geiss, W.D. Gill, J.F. Kwak, J.A. Logan, J.F. Rabolt, G.B. Street, J.C.S. Chem. Comm. (1979) 854.

2. H. Koezuka, S. Etoh, J. Appl. Phys. 54 (1983) 2511.

3. T. Ogama, H. Koezuka, J. Appl. Phys. 56 (1984) 1036.

4. P. Novák, W. Vielstich, J. Electroanal. Chem. 300 (1991) 99.

5. M.S. Kiani, G.R. Mitchell, Synth. Met. 46 (1992) 293.

6. M.J. González-Tejera, M.V. García, E. Sánchez de la Blanca, M.A. Raso, I. Carrillo, Thin Solid Films (in publication).

7. J.M. Charlesworth, A.C. Partridge, N.J. Garrard, J. Phys. Chem. 97 (1993) 5428.

8. L.L. Miller, Q.X. Zhou, Macromolecules 20 (1987) 1594. 
9. Q.X. Zhou, L.L. Miller, J.R. Valentine, J. Electroanal. Chem. 261 (1989) 147.

10. L.A. Prezyna, G.E. Wnek, Synth. Met. 41 (1991) 979.

11 J. Dumanska, K. Maksymiuk, Polish Journal of Chemistry 78 (2004) 1477 $-1491$.

12. U. Geißler, M.L. Hallensleben, L.Toppare, Adv. Materials 3 (1991) 104.

13. P.N. Barlett, R.G. Whitaker, J. Electroanal. Chem. 224 (1987) 37.

14. K. Maksymiuk,. Electroanalysis 8 (1996) 661.

15. A. Wojda, K. Maksymiuk, J. Electroanal. Chem. 424 (1997) 93.

16. A.Wojda, K. Maksymiuk, Electroanalysis 10 (1998) 1269.

17. K. Hyodo, M. Omae, Electrochim. Acta 35 (1990) 1245.

18. J. Ouyang, Y. Li, J. Appl. Polymer Sci. 59 (1996) 1827.

19. D.J. Shirale, V.K. Gada, P.D. Gaiwad, H.J. Kharat, K.P. Kakda, P.A. Savale, S.S. Hussaini, N.R. Dhumane, N.D. Shirsat, Mat. Letters 60 (2006) $1407-1411$.

20. R.J. Mammone, M. Binder, J. Electrochem. Soc. 137 (1990) 2135.

21. R. Singh, A.K. Narula, R.P. Tandon, A. Mansingh, S. Chandra. J. Appl. Phys. 80 (1996) 1476.

22. R. Singh, A.K. Narula, R.P. Tandon, A. Mansingh, S. Chandra, J. Appl. Phys. 80 (1996) 985.

23. G.R. Mitchell, F.J. Davis, C.H. Legge, Synth. Met. 26 (1988) 247.

24. G. Zotti, G. Schiavon, N. Comisso, Synth. Met. 40 (1991) 309.

25. E. Larraz, M.I. Redondo, M.J. González-Tejera, M.A. Raso, J. Tortajada, E. Sánchez de la Blanca, M.V. García, Synth. Met. 122 (2001) 413.

26. E.M. Genies, A. Syed, Synth. Met. 10 (1984/85) 21.

27. T.F. Otero, R. Tejada, S. Elola, Polymer 38 (1987) 651.

28. B. Zinger, Synth. Met. 30 (1989) 209.

29. I. Carrillo, E. Sánchez de la Blanca, M.J. González-Tejera, Polymer 42 (2001) 9447.

30. Y. Shen, J. Qiu, R. Qian, Makromol. Chem. 188 (1987) 2041.

31. I. Carrillo, M.J. González-Tejera, I. Hernández-Fuentes, Solid State Comm. 95 (1995) 107.

32. T.F. Otero, in "Modern Aspect of Electrochemistry" $\mathrm{n}^{\mathrm{o}}$ 33. R.E. White (Ed.), Kluwer Ac. (1999) New York.

33. M. Fuchiwaki, W. Kakashima, K. Kaneto, Jp. J. Appl. Phys. Part. 140 (2001) 7110.

34. G.M. Spinks, G.G. Wallace, L. Liu, D. Zhou, Macromol. Symp. 192 (2003) 161.

35. K. Hyodo, M. Omae, J. Electroanal. Chem. 292 (1990) 93.

36. A. Cambra, M.I. Redondo, M.J. González-Tejera, Synthetic Metals 139 (2003) 21.

37. A. Díaz, J.J. Castillo, J.A. Logan, Y.W. Lee, J. Electroanal. Chem. 29 (1981) 115.

38. T. Schimidzu, A. Ohtani, T. Iyoda, K. Honda, J. Electroanal. Chem. 224 (1987) 123.

39. R. John, G.G. Wallace, J. Electroanal. Chem. 306 (1991) 157. 